\title{
Legados, peregrinos del tiempo, memorias ocultas: una mirada transgeneracional a través del cine
}

Legacies, pilgrims through time, hidden memories: a transgenerational look through cinema.

Margarita Kupferminc

Instituto de Psicoanálisis, Argentina

margakup@yahoo.com.ar

\section{Resumen}

El sujeto nace inmerso en un grupo familiar, portador de creencias, ritos, normas; y también secretos y memorias ocultas. Son legados que viajan a través de las generaciones y encuentran diferentes y múltiples modos de manifestarse.

A partir de Freud y la teoría psicoanalítica, el sujeto es convocado a pensarse como sujeto de una herencia que hace un aporte a lo recibido transgeneracionalmente.

Se realiza una investigación bibliográfica sobre el tema. Se propone el uso del dispositivo cinematográfico para contribuir a la ampliación de la escucha y comprensión del analista en el trabajo con el analizante para ayudarlo a reparar traumas.

El método empleado en el presente trabajo consiste en la realización de un recorte de la película "Un secreto" que evidencia lo que se quiere demostrar.

Se demuestra cómo la violencia social y situaciones silenciadas $u$ ocultas, se transmiten aún sin palabras y pueden ser generadoras de traumas; pues hay un vínculo dialéctico entre la singularidad del sujeto y el legado cultural en el que adviene.

La Shoah, conocida como Holocausto, constituye el paradigma de horror supremo cometido por seres humanos a otros seres humanos. Sus consecuencias permiten pensar todas las formas que toma la violencia social.

Palabras clave: Legados. Secretos. Transmisión Transgeneracional. Psicoanálisis. Holocausto. Violencia social. 
Legacies, pilgrims through time, hidden memories: a transgenerational look through cinema.

The human subject is born immersed in a family, he is the carrier of beliefs, rites, norms; as well as of secrets and hidden memories.

These are legacies that go through the generations and find different and multiple ways of manifesting themselves.

From Freud and his psychoanalytic theory onwards, human beings are called to think of themselves as heirs of a legacy that in each generation make a contribution to the transgenerational inheritance.

A bibliographical research is carried out and the use of the cinematographic device is proposed, to contribute to the expansion of analytical listening and comprehension of the analysand within the framework of the session.

The method used in the present work consists in the realization of a fragment of the film "A secret" that shows what is wanted to be demonstrated. That social violence and silenced or hidden situations are transmitted even without words and can be generators of traumas; for there is a dialectical link between the singularity of the individual and the cultural legacy in which the human subject arises.

The Shoah, known as the Holocaust, constitutes the paradigm of supreme horror committed by human beings to other human beings. Its consequences offer the possibility to think about all the forms that social violence takes.

Keywords: Legacies. Secrets. Transgenerational Transmission. Psychoanalysis. Holocaust. Social violence .

\section{Introducción}

"Nuestra tarea en el mundo no es entender el mundo. Nuestra tarea es la incomprensión. La tarea del escritor es escribir las secuelas de esa 


\title{
incomprensión; la del poeta, hurgar en las profundidades del incomprendido; la del músico, proferir un arañazo en la materia de la nada".
}

Imre Kertesz

\begin{abstract}
¿Cuál es la tarea del psicoanalista?
¿Un poco la del poeta que hurga para encontrar y ligar los fragmentos surgidos de las profundidades del ser?, ¿la del músico, porque araña en la materia de la nada, en el intangible inconsciente?, ¿la del escritor en el acto de acompañar y cooperar con el analizante en la historización y simbolización; y en la transmisión del arte y los efectos de la tarea que realiza?
\end{abstract}

Surge otra pregunta: ¿Qué es lo que cada generación lega, transmite a la siguiente y cómo influye esto sobre cada sujeto en la cascada generacional?

Nos proponemos investigar mediante el aporte del recurso cinematográfico ${ }^{1}$, los efectos que producen en el individuo: los legados, es decir la transmisión inter y transgeneracional, de ritos, creencias, costumbres, normas; y también secretos, entre otros. Pensamos que la consideración de la dimensión transgeneracional contribuiría a ampliar la escucha psicoanalítica, en el marco de la sesión con el consultante.

A veces, los secretos fluyen en la corriente del tiempo, como una cascada a través de las generaciones; hasta que en algún momento encuentran diferentes modos de manifestación, que constituyen las "marcas" de actos concernientes a generaciones precedentes.

\section{Psicoanálisis y cine}

Realizamos una puntuación de la película "Un secreto" y proponemos una lectura de la misma, que pone de manifiesto las implicancias del acto de legar, propio del ser

\footnotetext{
${ }^{1}$ Se realizó un recorte del material fílmico utilizado en la monografía, al que se puede acceder de la siguiente manera: 1- link: bit.ly/monografíalegados. 2- Youtube: Legados, peregrinos del tiempo
} 
humano desde múltiples dimensiones. Una de ellas es la transmisión; sea ésta consciente o inconsciente, material o inmaterial, concreta o abstracta, sonora o silenciosa.

Creemos que el arte y el psicoanálisis son dimensiones culturales y por tanto humanas que se implican mutuamente por cuanto son creaciones que a su vez crean al sujeto.

El cine es una expresión artística visual, multidimensional; que reúne diversos lenguajes: la imagen, la literatura, el teatro, la pintura, la arquitectura, la poesía, la música y el movimiento; y ofrece al sujeto la posibilidad de participar de escenas que despliegan interrogantes, dudas, conflictos; y de este modo el cine abre puertas y ventanas para atisbar a través de diversos mecanismos, como la identificación, la proyección, la transferencia, la interpretación, el análisis; los enigmas y circunstancias, que surgen para el psicoanálisis en relación a su objeto.

Generalmente, refleja la trama mítica y las creencias que sostienen la estructura sobre la que se construye la sociedad y el imaginario colectivo. Puede actuar como posibilitador de catarsis, de descarga de tensiones, a través de la presentación de modelos identificatorios y arquetipos culturales. De este modo, como se ha mencionado, intentamos señalar, mediante el recurso cinematográfico, cómo los secretos de familia y la violencia social, afectan tanto en la vida del individuo como así también en sus descendientes.

Desde la perspectiva del psicoanálisis, en Psicología de las masas y análisis del yo (Freud, 1921), leemos que la identificación es la más temprana exteriorización de una ligazón afectiva con otra persona.

Laplanche (1996) define la identificación como "un proceso psicológico mediante el cual un sujeto asimila un aspecto, una propiedad, un atributo de otro y se transforma, total o parcialmente sobre el modelo de éste.

Dice Freud (1913): "Lo que el artista busca, en primer lugar es autoliberación, y la aporta a otros que padecen de los mismos deseos retenidos al comunicarles su obra". 
Entonces, el ejercicio del arte es una actividad que tiende a mitigar los deseos insatisfechos tanto del artista como así también del espectador de la obra, ambos mancomunados por la insatisfacción.

Daniel Zimmerman (2000), en su libro Contornos de lo real menciona que en su investigación acerca de la relación de Freud con el cine como expresión articulada con su teoría, no encontró referencia a un particular interés del padre del psicoanálisis por el séptimo arte. Sin embargo en el transcurso de las Lecciones de Introducción al Psicoanálisis (1915) Freud señala: "Los que rodean al enfermo (se refiere a sus familiares), poco ilustrados, sólo admitirán las bondades de un tratamiento que presente efectos visibles y tangibles como los que se ven en el cinematógrafo". Podemos leer en esta afirmación cierto reconocimiento del poder de convicción de la imagen fílmica, no sin destacar la condición de "poco ilustrados" de los supuestos incrédulos.

Para Lacan, dice Zimmerman (2000), lo esencial es la convicción de la obra fílmica, la misma debe ser creíble y los personajes deben ser considerados en su condición de plenos sujetos en el universo simbólico que el film constituye.

\section{El hechizo del cine}

Como espectadores, nos disponemos a ingresar en el despliegue de escenas que el autor propone. Siempre hay algo de mágico en el momento en que, sea en el cine o en el ambiente que opera de espacio de proyección, las luces se apagan, los sonidos sugieren y mágicamente las primeras imágenes nos transportan hacia lo que será nuestro viaje a través de otras vidas, las vidas de otros, en las que algo afín hará consonancia y también habrá disonancias con nuestro propio vivenciar.

El encuentro del espectador con lo que la película propone, provoca un hecho vivencial, entendiendo por vivencia (Erlebnis), esa forma peculiar de la vida, que tiene la virtud de permitir un acceso al conjunto de la experiencia humana libre de intelectualismo. Es un momento de sensible vivenciar, que tal vez explique en parte, el efecto cautivador, fascinante del espacio cinematográfico. 
El dispositivo cinematográfico, constituye el medio de transporte que coopera con establecer una relación íntima entre lo que aparece proyectado en la pantalla y quien la observa en su carácter de espectador.

En la pantalla las imágenes hilvanan una trama que al mismo tiempo que encubre, revela algo que se da a ver. Hay un velo que cubre y a la vez desenmascara; y hay una mirada que goza alimentándose con las imágenes. La película se convierte en señuelo convocante de la mirada del espectador.

Algo en la película se entrega para saciar la mirada. Así lo que proporciona el encantamiento a la secuencia cinematográfica es "el apetito de ese ojo que hay que alimentar". (Daniel J. Zimmerman, 1993). Enmarca una escena que fascina y hace cuadro a un tema. En la pantalla la verdad se presentifica con estructura de ficción. Lo verosímil debe ser convincente y transformarse en "verdad".

Es por eso que el cine como recurso ofrece la posibilidad de transmitir la clínica ligada al psicoanaálisis. El espectador mira, configura y recorta; participando de una suerte de interjuego con el recorte realizado por el director.

Dice Italo Calvino:

Cuando entraba al cine, al salir me golpeaba el paso del tiempo, el contraste entre dos dimensiones temporales diferentes, la de adentro y la de afuera de la película...la oscuridad atenuaba un poco la discontinuidad entre los dos mundos y a la vez la acentuaba, porque marcaba el pasaje de esas dos horas en que me había sumido en el tiempo suspendido, o en la duración de una vida imaginaria, o en el salto hacia atrás en los siglos. Fudín, Mónica. $(2005)^{2}$

Pensamos que la articulación entre el psicoanálisis y el cine, a través de los personajes que encarnan los actores y de la trama argumental de cada obra, puede ser instrumento

\footnotetext{
${ }^{2}$ Fudín, Mónica: Psicoanálisis y Cine: Arte, artista y espectador. Internet. (2005)
} 
de transmisión de la clínica y un aporte a la comprensión de conceptos psicoanalíticos; lo que constituye en sí mismo, uno de los legados del cine al psicoanálisis, en el sentido de contribuir con la transmisión de diferentes modos de vivir, en diferentes tiempos históricos, distintos ámbitos culturales; y de este modo, se enriquece la comprensión de lo que somos, de nuestras tendencias, deseos e ilusiones.

\section{Legado}

Una palabra puede tener múltiples significados, los términos son polisémicos. Por eso cuando nos comunicamos, es necesario, aclarar desde dónde estamos diciendo lo que decimos para disminuir de este modo, el inexorable malentendido inherente a la comunicación. Por eso, en todo discurso, es fundamental la comprensión de un concepto según el sentido que tenga dentro del contexto específico en que se emplea.

Un legado es lo que se deja o transmite, y se ofrece, a los sucesores, sea cosa material o inmaterial (Gran diccionario Salvat, 1992)

En la Biblia, Éxodo 20:5, dice: "Yo soy el Señor, tu Dios...que castigo la iniquidad de los padres en los hijos hasta la tercera y cuarta generación”. En Ezequiel 18:2 se lee: "Los padres comen uvas verdes y los dientes de los hijos padecerán dentera". Estas aseveraciones intentan resaltar que los actos de cada sujeto no son sin efecto.

¿Cómo interpreta el psicoanálisis estas aseveraciones?, ¿Habría responsabilidad de los hijos en la reparación de los errores o perjuicios cometidos por los padres?

El psicoanálisis, teoría que, entre otras cosas, se ocupó de desarrollar lo referente a lo intrapsíquico del sujeto, ¿podrá también explicar lo concerniente a la transmisión de la psique, o producción intersubjetiva de la psique, como lo denomina René Kaës (1993)? ¿Cómo concebir al sujeto en tanto, como dice Freud "El sujeto es para sí mismo su propio fin y también es eslabón en la cadena generacional?", es decir, es heredero de generaciones que lo preceden. 


\section{EI Legado de Freud}

En el caso del legado freudiano, el autor ofrece su obra, para que de ella, cada cual tome lo que considere según la necesidad y continúe con la investigación. No cabe duda que el legado de Freud es el psicoanálisis; pero ¿qué es el psicoanálisis? Son múltiples las corrientes post-freudianas que sostienen sobre los fundamentos de Freud, conceptos originales y algunos aportes diferentes.

¿Y quién es el heredero de su legado? Pensamos que todas las diferentes ramas de las ciencias, el arte y el pensamiento en general, se encuentran de algún modo involucrados en los efectos que el paradigma freudiano legó a la humanidad. Es el desarrollo de un pensamiento que tuvo por objetivo aliviar el sufrimiento (neurótico) del ser humano.

Freud partió del presupuesto que mediante el trabajo psicoanalítico se podían recuperar para la consciencia aspectos humanos sumergidos bajo los estratos de la evolución de la cultura. Denominó inconsciente a la dimensión humana sumergida, contenedora de aspectos de la sexualidad infantil, reprimidos y ligados con lo que explicitó a través del concepto denominado Complejo de Edipo.

Pero ha pasado mucho tiempo desde entonces y surge la pregunta... ¿Y hoy?, ¿cómo es la teoría a la luz de los tiempos que corren? ¿Qué cosas, de la obra de Freud, siguen vigentes?, ¿Cuáles ya no se sostienen?, ¿Explica la teoría aspectos no tenidos en cuenta en su origen sino surgidos en el devenir del pensamiento? Ante tantos interrogantes, Freud deja como legado además de la teoría, la apertura de la misma a futuras investigaciones (Freud, 1939).

En algunos casos lo que se recibe como legado no se siente como propio y esto tiene consecuencias como podría ser, la pérdida de lo recibido, malestar; y ya en el prólogo del Esquema (1939), Freud refiere que quien recibe un legado debe apropiarse del mismo. Es decir, transformarlo en propio a través de su aporte personal a lo legado. Al respecto dice: "Las enseñanzas del psicoanálisis se basan en un número incalculable de observaciones y experiencias, y sólo quien haya repetido esas observaciones en sí 
mismo y en otros individuos está en condiciones de formarse un juicio propio sobre aquél”. (Freud, 1939. Pág. 139)

Cuando el consultante se dispone al psicoanálisis, generalmente lo hace motivado por el anhelo de resolver conflictos muchas veces alimentados por síntomas (neurosis) que van horadando su desempeño general.

El análisis opera facilitando que el analizante pueda encontrar en sí mismo aquellos contenidos que él "no sabe que sabe".

La formación en psicoanálisis permite al psicoanalista obtener una noción de los contenidos universales del ser humano, pero no sabe de la singularidad del analizante, constituida por el modo particular de la experiencia individual y por cómo él, se apropió o no, de lo que de sus padres heredó y adquirió; sumado a lo que la vida le aportó. Para lograrlo, el analista emplea el método de la libre asociación y la atención flotante.

En lo concerniente a la transmisión psíquica, Freud habló de una herencia psíquica, social, religiosa y cultural.

Inicialmente interroga la vía psíquica de lo heredado de las neurosis y conceptualiza a través del descubrimiento del complejo de Edipo. Luego considera la posición del sujeto como heredero de la culpa de los ancestros en su obra Totem y Tabú (1912-1913).

En un tercer momento desarrolla el tema de los duelos impuestos por las guerra, la violencia; centrándose en la transmisión intrapsíquica e intersubjetiva. Posteriormente escribe Psicología de las masas y análisis del yo (1921). Así, desde Freud en adelante, el sujeto es convocado a pensarse como sujeto de una herencia y como tal, de la diferencia que aporta a lo recibido de sus padres. Así lo expresa Freud, con palabras que Goethe pone en boca de Fausto:

Was du ererbt von deinem Vätern hast, Erwirbes, um es zu besitzen. 
"Lo que has heredado de tus Padres, para poseerlo, gánalo".

En Introducción del narcisismo (1914), Freud describe al sujeto singular como eslabón, servidor, beneficiario y heredero de la cadena intersubjetiva de la que procede. Esto hace que el sujeto del Inconciente, sea sujeto de la herencia y sujeto del grupo de pertenencia en el que nace.

En el presente trabajo, a partir de la película "Un secreto" nos proponemos articular conceptos psicoanáliticos con lo simbólico, adjudicando un sentido a las escenas que el director propone y el espectador recorta acorde a su subjetividad ${ }^{3}$

\section{Película "Un Secreto": Síntesis y articulación con la teoría psicoanalítica}

\section{Ficha técnica}

(Director : Claude Miller País: Francia. Año: 2007. Duración: 105 min. Género: Drama. Guionistas : Claude Miller, Natalie Carter Autor de la obra original : Philippe Grimbert. Director de fotografía/imágen : Gérard Battista Ingeniero de sonido : Pascal Armant, Fred Demolder Director de produccion : Sylvestre Guarino Encargado de prensa (pelicula) : Christopher Robba.

Interpretación: Cécile de France, Patrick Bruel, Ludivine Sagnier, Julie Depardieu, Mathieu Amalric, Nathalie Boutefeu, Yves Jacques, Sam Garbarski, Orlando Nicoletti, Valentin Vigourt, Robert Plagnol, Eric Godon, Philippe Grimbert, Quentin Dubuis, Myriam Fuks, Michel Israel, Arthur Mazet, Annie Savarin, Yves Verhoeven.)

Francia, en la década del 50. François Grimbert, está convencido de ser una permanente fuente de desilusión para su padre y su madre.

La superficie velada de un espejo, va reflejando a medida que se aproxima, la imagen frágil, vulnerable de un niño. Camina hacia delante, como "flotando sobre las huellas de

\footnotetext{
${ }^{3}$ Antes de continuar con la lectura, la autora aconseja proyectar el video con sinopsis de la película "Un secreto", sobre los temas tomados en la monografía y ver la hoja con el genograma que se encuentra al final del artículo. Los videos pueden encontrarse en los siguientes sitios:

1- bit.ly/monografía legados

2- 2- You Tube: Legados, peregrinos del tiempo.
} 
la memoria”, así describe el protagonista adulto, su sensación de inadecuación durante la niñez, porque sentía que no respondía a lo que sus padres esperaban de él. A medida que se desarrolla la trama de la película, se revela que la situación planteada se sostiene sobre un secreto guardado en la vida de sus padres.

François Grimbert es quien narra la historia en 1985, cuando ya siendo psicoterapeuta, durante un viaje en tren, repasa introspectivamente, su vida. El autor a través de diferentes momentos de la historia familiar, desarrolla el conflicto a la manera de una tragedia griega.

Desde una mirada de la trama como proceso psicoanalítico, podríamos decir que el aspecto trágico que indica que con la sangre se hereda un destino, se presenta en el síntoma del pequeño François quien irá develando enigmas familiares que lo llevan a bordear zonas oscuras de las cuales finalmente, consigue emerger y constituirse en sujeto.

La narración comienza en verano de 1955, con imágenes de la díada Madre - niño. Ella es atlética, segura, bella. El niño es frágil, lábil, torpe, inseguro.

Periódicamente y en diferentes circunstancias, François percibe la presencia de un personaje fantasmático, se trata de un niño, que él ha inventado, con el que se comunica y juega. Es fuerte, deportista; y tiene cualidades físicas absolutamente contrapuestas a las suyas; sobresale por su destreza, realiza actividades acrobáticas. Representa un ideal que François no puede encarnar para la mirada decepcionada de su padre, profundamente herido en su narcisismo ante la frustración de sus expectativas incumplidas.

“A pesar de ser hijo único, desearía tener un hermano", dice François.

François, nace en tiempos de posguerra, en el seno de una familia en la que la ambigüedad identitaria se pone de manifiesto en múltiples escenas: Maxime, el padre rechaza su linaje judío, y trata de diferenciarse a través de la exaltación del desarrollo y la destreza corporal según los ideales de la raza aria ("esperaba que el deporte le 
permitiera borrar sus orígenes"), bautiza a su hijo, quien por su edad, nota que es más grande que los otros niños que participan del mismo rito. Se habla en la familia de que este hecho (el bautismo) debe ser omitido delante del abuelo porque como dice su madre Tania, al abuelo "lo entristece hablar de iglesias y cementerios". Además, el padre nacionaliza su apellido cambiando Grinberg por Grimbert, "con M y T", aclara con énfasis.

El presente en blanco y negro, alterna con las imágenes coloreadas del pasado, y con este recurso el talento del director va trazando en la narrativa el proceso de historización del agujero instalado en la memoria de François.

Louise, una amiga íntima de la familia, es el personaje que cataliza este trabajoso proceso que atraviesa François.

Un juguete prohibido, reiteradas pesadillas, complicidades encubiertas, aunque reveladas en las miradas que entrecruzan los adultos; son indicios de un inquietante y enigmático pasado.

Pasado que una y otra vez, retorna constantemente para reflejar, la frágil imagen del ahora adolescente, en la superficie espejada.

“¡No quiero ser judío!”, afirma con fastidio cuando Louise indaga acerca de la identidad de una compañera de la escuela que simpatizaba con él. Sin embargo, una fuerza pulsional irrefrenable (¿o será, según Lacan, la voz del Otro?) lo incita a reaccionar con violencia contra un compañero que se burla de las imágenes que muestran lo acaecido en los campos de concentración. François se siente provocado; "quise matarlo" confiesa mientras Louise le cura las heridas.

Heridas en el cuerpo y heridas del alma, ya que el amor de Louise por François la llevan a transgredir el pacto de silencio familiar, hasta ese momento, sellado; y le revela el secreto encriptado en la historia familiar.

Como dice Jaques Hassoun (1994), en Deuteronomio leemos; "Pregunta a tu padre y él te responderá (tu historia) y pregunta a tus ancianos y ellos te dirán (lo que fue tu 
pasado)". Inferimos de este mandamiento que la necesidad de transmitir, hace milenios está inscripta en la Historia.

De esta manera, Louise valida los sentimientos de François, hace lugar a ellos y él se abre a los interrogantes que empujan sus pulsiones (transferencia, amor de transferencia que posibilita la apertura, corrimiento de un velo que revela). Louise representa la bisagra que facilita mover el velo que cubre el enigmático agujero de la memoria.

Vemos como luego de una crisis de François, aparece un padre que, por primera vez, mira con satisfacción la respuesta de su hijo a la agresión de sus compañeros, esos otros que pusieron en evidencia el sentimiento de ajenidad que despierta el odio.

François ha logrado atraer la atención de su padre.

Es así como Simón encarna el fantasmático hermano al que François daba vida mediante su imaginación. Aparece en escena junto a Hanna, primera esposa de su padre y cuñada de Tania (madre de François), que en primeras nupcias estuvo casada con Robert (hermano de Hanna).

Hubo un instante a partir del cual nadie pronunció más, sus nombres.

Entre Tania y Maxime fluye, desde el primer encuentro una corriente de atracción que ya no pueden disimular ante las miradas suspicaces del entorno.

Mientras tanto la situación de los judíos en París empeora, Robert muere en el frente. La familia decide huir de Francia y Tania se reúne con Maxime, su cuñado, en un refugio más allá de la frontera, hasta tanto se produzca el planificado reencuentro con Hanna y Simón, que llegarían un poco después, junto a Esther y Louise.

Pero al enterarse Hanna de que sus padres han sido deportados y que Tania y Maxime ya están juntos, la situación se vuelve intolerable para ella y se repliega, aislándose, como emocionalmente encapsulada en otra dimensión. Parece abstraída, alienada. 
En una parada, durante la huída hacía la frontera que debía conducirlos a la salvación, el control policial le pide la documentación, y Hanna entrega el pasaporte auténtico que denuncia su identidad judía y también identifica a Simón, “es mi hijo", les dice. Los detienen y deportan ante la mirada absorta y desesperada de Louise y Esther.

¿Se trata de un pasaje al acto dedicado vengativamente a Maxime y a Tania?

Imágenes en blanco y negro nos transportan nuevamente a 1985; la correa de un perro muerto accidentalmente, provoca el advenimiento del pasado, hasta ese momento ahogado en la oscuridad del silencio y estalla en el acto de fuga de un Maxime viejo, abrumado por la culpa.

Le avisan a François que su padre había sacado a pasear a su perro Fox Terrier sin correa, y un automóvil accidentalmente, atropelló al perro. Luego de depositar a su perro muerto, en la casa, Maxime salió y habiendo transcurrido tres horas desde el hecho, no había regresado aún.

François encuentra a su padre sentado pensativo en un banco de plaza, su perro se había escapado: "Nunca lo vi tan triste, se recuperó de lo de Hanna y de Simón, pero lo del perro lo aplastó", narra François.

Maxime toma la correa del perro y dice; "no murió enseguida, debe haber sufrido", ¿A quién se refiere al perro, a Simón, a Hanna...?

Maxime agrega: "Es culpa mía", y entonces su hijo le responde que sí, que era culpable de la muerte de su perro, no de la de Simón. François trata de consolar a su padre diciéndole que el odio nazi fue el único culpable de lo acontecido. De este modo intenta liberar a su padre de su secreto.

François luego investiga, averigua el destino que corrieron Hanna y Simón y ante la evidencia hallada en los registros, lleva los datos a un investigador que está escribiendo un libro sobre el tema. Éste le pregunta quién es Simón, y François responde: “soy su 
hermano", lo nombra, asume su filiación, el significante hace presente la ausencia, hubo proceso de simbolización.

En la escena final, el director muestra el presente en colores, representando tal vez, el efecto de la luz sobre la oscuridad fantasmática y se ve a François visitando en compañía de su pequeña hija, un cementerio de perros en los jardines del chateau de la hija del presidente Laval. Las investigaciones llevadas a cabo por François, revelaron que fue éste el ejecutor de la muerte de Hanna y Simón.

En ese momento es cuando François decidió contar su historia y sacar a todos los fantasmas del oscuro silencio.

En el epílogo de la película se relata que Maxime "no pudo tolerar ver la invalidante secuela de un ataque cerebro vascular que sufriera Tania, su bella nadadora, y decidieron terminar"'.

\section{Algunas reflexiones sobre la historia que la película nos narra.}

La película habla de un psicoanalista (o psicoterapeuta) que intenta operar en sus pacientes (niños), algo del proceso que él mismo debió atravesar para superar las profundas heridas y marcas que su experiencia en la niñez y acontecimientos acaecidos aún antes de su nacimiento, le ocasionaron.

Leemos en El malestar de la cultura (1931, p. 79), que una técnica para tomar distancia del sufrimiento consiste en el desplazamiento de la libido hacia otras metas pulsionales y el trabajo psíquico e intelectual, se constituye en fuente de placer. El psicoanálisis también ofrece como recurso para trascender la pulsión de muerte, la sublimación. (Peskin, 2003).

En construcciones en el análisis, (Freud, 1937, p. 261), se compara el trabajo del analista con el del arqueólogo que a partir de fragmentos que va hallando, reconstruye situaciones arcaicas; y así también el analista, a partir de recuerdos, asociaciones y actos del analizando, efectúa construcciones de lo acaecido en tiempos que posiblemente haya olvidado o incluso hayan precedido su nacimiento. 
En la Carta 52 de la correspondencia que Freud (1896) mantuvo con Fliess, Freud menciona y explica el mecanismo por el cual situaciones que precedieron la existencia del sujeto, es decir pertenecientes a su prehistoria, tienen efecto en generaciones posteriores; es decir, transgeneracionalmente.

Explica que el psiquismo se constituiría por estratificación sucesiva comenzando por la percepción en el polo perceptivo y culminando en el polo del otro extremo de su esquema, con la representación-palabra. El mecanismo se produciría a través de sucesivas transcripciones o copias hasta llegar a ligarse, dichas percepciones a las representaciones-palabras, situadas en el preconciente y sólo asequibles a la conciencia, en un momento secundario, de efecto posterior. También leemos que estas estratificaciones suceden en diferentes épocas de la vida y que cada una de ellas inhibe a la anterior pero quedan "relictos", lugares donde se guardan recuerdos que testimonian excitaciones que no han podido ser tramitadas. Podríamos decir que el material perceptivo sería transcripto, copiado; pero quedarían partes que no habiendo sido ligadas a representaciones-palabra, no habrían sido tramitadas.

En El Esquema, capítulo V, Freud nos habla de los sueños. François, durante un viaje en tren, tiene la mirada fija en un punto perdido y como sucede cuando soñamos despiertos, las imágenes traen recuerdos que seguramente el protagonista ha ido recuperando durante el trabajo de reconstrucción de su pasado, incluso del acaecido cuando él aún no había nacido. Muchas de las escenas son parte de lo que Freud denominó la "herencia arcaica" que el niño trae congénita al mundo, anterior a cualquier experiencia propia e influido por las vivencias de los antepasados (El Esquema, 1939, p. 165)

En Moisés y la religión monoteísta (1939, p. 96), Freud admite la influencia de la herencia arcaica en la formación del psiquismo del individuo. Lo atribuye a que habría cierta predisposición constitucional que lo liga a la herencia filogenética y dice: "la herencia arcaica del ser humano no abarca sólo predisposiciones, sino también contenidos, huellas mnémicas de lo vivenciado por generaciones anteriores". 
Lacan en uno de sus primeros libros, La Familia (1977) habla de la familia como transmisora de cultura a través de la educación y la transmisión de la lengua. La familia, como agrupación humana que conforma la sociedad al mismo tiempo que es modificada por los cambios que se suceden en su devenir, es atravesada por mitos, no sólo los universales, sino también por mitos singulares de cada familia y más aún, de cada individuo.

Cuando los mitos constituidos por relatos, creencias, silencios; son interrogados surge la posibilidad de "atar cabos", "rellenar agujeros o lagunas", ir hilvanando fragmentos o retazos de la historia familiar e individual del sujeto; en la búsqueda de un sentido para lo que aparece como un sinsentido o en la historización y resignificación de lo acontecido o aconteciendo.

En El mito individual del neurótico Lacan destaca la importancia de las situaciones que precedieron al nacimiento del sujeto, de los lazos familiares, de la circulación del deseo en el grupo familiar; en relación a la evolución de sus neurosis.

A través del lenguaje el niño, se incorporaría al orden humano, hasta llegar a ubicarse en la posición masculina o femenina, como su padre o su madre y sus antepasados. También llegan al niño los efectos de situaciones ocultas, no dichas.

Un niño, aún antes de su concepción, es pensado y deseado o no, por sus padres. Es decir, que la historia libidinal y vincular de sus padres influye inconscientemente en la estructuración de su psiquismo.

Desde su nacimiento, el niño ingresa en la cultura recibiendo su influencia por medio de sus primeras percepciones y de este modo inicia la estructuración de su psiquismo. Freud menciona las "series complementarias" (1916-1917) que dan cuenta de la relación entre la singularidad de cada sujeto; con su entorno y con lo que lo antecedió.

La subjetividad individual debe ser pensada en relación a la subjetividad colectiva, del grupo, social, del conjunto. No se trata de la dualidad individuo Vs. grupo, sino de una 
relación dialéctica. Debemos pensar al sujeto psíquico como inseparable de la intersubjetividad.

François es un niño que muestra actitudes que denotan su inseguridad, temores y síntomas que exasperan a su padre. Se podría inferir que en cierta época de su vida ha atravesado experiencias con probable influjo en los síntomas evidentes; y es precisamente sobre la época de la vida, lo que refiere Freud en El Esquema (1939, p. 184), como factor esencial para la adquisición de las neurosis.

Los padres de François, atravesados por duelos en suspenso no pueden contener las angustias existenciales de su hijo. Entonces François vive en forma fantasmática, el sufrimiento de sus padres. Frente a la ausencia de palabras que den sentido al sufrimiento que padece, crea por sí mismo contenidos y se los apropia; introduciéndose así, en la constelación traumática de los padres. A través del síntoma, François interroga a sus padres y a Louise.

Como ya se ha mencionado, en Introducción del narcisismo (1914), Freud dice "El individuo lleva realmente una existencia doble, en cuanto es fin para sí mismo y eslabón dentro de una cadena de la cual es tributario contra su voluntad, o al menos, sin que medie ésta".

La predisposición hereditaria junto a la educación e influencia de progenitores y maestros, limitan la actividad del Yo mediante prohibiciones y castigos y nutren también, la génesis de las neurosis.

En El Hombre de los lobos (1917-1919), Freud dice que no es muy importante precisar si el paciente tiene fantasías o si sus vivencias son reales; lo que observa es que en la historia primordial de las neurosis cuando el propio vivenciar no alcanza, el niño toma la vivencia filogenética. Llena las lagunas de la verdad individual, con una verdad prehistórica, pone la experiencia de los ancestros, en el lugar de la propia. 
En el caso particular de François, esto es evidente a través de expresiones de un yo "endeble, inacabado e incapaz de resistencia", que por lo tanto, no puede superar tareas exitosamente, mediante la tramitación del juego.

Exigencias pulsionales internas sumadas a excitaciones provenientes del mundo exterior, ejercerían el efecto traumático. El yo desvalido se defiende intentando huir y podemos considerar que François lo hace a través de la ensoñación en la que surge la figura de otro niño, idealizado, con las_cualidades y características que sus padres proyectan en él y que éste no consigue satisfacer.

En la película el director nos muestra un niño caminando hacia el encuentro de una imagen velada en el espejo; escena que se repite en el ingreso a la adolescencia; nuevamente se busca y aún no encuentra nitidez. Su imagen narcisística vacila, amenaza aún desintegrarse.

\section{Comentarios sobre algunas investigaciones}

En la película que consideramos hay "un secreto" que encubre la transgresión de una legalidad, de una ley familiar que no se cumplió; que posiblemente inundó el psiquismo de François, no pudo ser ligado y devino en trauma.

Desde su concepción y durante su crianza, François es receptor de los efectos que provocan experiencias intolerables para sus progenitores, por lo que se silencian y pasan de una generación a la siguiente, sin palabras pero percibidas a través de gestos, mandatos y tradiciones. La falta de palabras impide la ligazón dentro de una cadena significante e impide la tramitación simbólica.

Maud Manonni (1967), en El niño, su enfermedad y los otros, dice: "El niño aparece como el soporte de los fantasmas y el voyeurismo de los adultos. Se mueve en un mundo en el cual lo "no dicho" expresa una dificultad, un drama en la pareja de los padres, drama percibido muy claramente por el niño". Y lo traumatizante es lo 
silenciado, ubicándose el síntoma en el lugar de la palabra que falta. (Diacovetzky, 2007)

François adolescente protagoniza un episodio de lo que hoy se denomina bullying que lo coloca a posteriori, ante el interrogante que podríamos formular como "quién soy?" Algo del orden del "a", función causa de deseo, lo impulsa hacia una reconstitución de su yo a través de su trabajo como analista con el otro semejante. El otro con minúscula, que cuando logra derribar el muro del lenguaje, a través de palabra, accede al Otro con mayúscula, ese lugar, tesoro de los significantes.

Jaques Hassoun (1994) en su obra "Los contrabandistas de la memoria" dice que la transmisión constituiría ese tesoro que cada uno se fabrica a partir de elementos brindados por los padres, por el entorno y que remodelados por encuentros azarosos y por acontecimientos que pasaron desapercibidos, se articulan a lo largo de los años con la existencia cotidiana para desempeñar su función principal: ser fundante del sujeto y para el sujeto (Pág. 121)

En la película, podemos considerar algunos significantes:

- Miradas cómplices y suspicaces

- Ceremonia de bautismo

- Cambio de apellido

- Perrito de juguete

- Perro muerto

- Correa de perro

- Lápidas de los perros en el jardín de la hija del jerarca nazi

- Nombres de los perros de los nazis, nombres de las víctimas de los nazis

Estos serían los contrabandistas de la memoria, los significantes, que transgrediendo la frontera de la represión, condujeron a François al límite del abismo o agujero que fue zurciendo, suturando; a través del trabajo creativo, sublimatorio que logró realizar a lo largo de su vida (Jacques Hassoun, 1994). 
René Kaës (1993), menciona que N. Abraham y M. Torok, durante la década de 1970, investigaron sobre el duelo, la cripta, el fantasma, poniendo el acento sobre el defecto en la trasmisión (forclusión, encriptado, rechazo), resaltando el papel del secreto, de la no-simbolización. Destacan que la trasmisión no cesa de efectuarse y se produce, a veces, el enquistamiento en el Inconciente de un sujeto, de una parte de las formaciones inconcientes de otro, que llega a habitarlo como un fantasma.

Las investigaciones clínicas y teóricas se dirigieron a analizar el modo como se trasmiten los síntomas, los mecanismos de defensa, los significantes; y cómo los objetos y procesos de trasmisión psíquica van estructurando correlativamente el vínculo intersubjetivo y la formación del sujeto singular.

Se intenta articular las formas y los procesos de la realidad psíquica de un sujeto considerado en su singularidad, con las formas y procesos de la realidad psíquica que se constituyen en los vínculos intersubjetivos.

En estudios realizados por Nicolas Abraham y María Torok y también Tisseron, los autores llaman hechos "encriptados" a aquellos que a pesar de haber acaecido en generaciones anteriores que los mantuvieron en secreto, tienen influencia en las subsiguientes, a las que llegan en forma conciente o inconciente como mensajes que producen efectos en quien los recibe.

El acontecimiento "encriptado" es "indecible" (yo lo llamaría "no dicho") pues está presente en quien lo ha vivido pero no puede hablar de ello.

En la generación siguiente, el niño es portador de un "fantasma" que no le pertenece ni puede nombrar ya que para él no tiene representación verbal (yo lo llamaría “indecible”). Ignora sus contenidos pero "algo" interroga en su psiquismo.

El acontecimiento de la "cripta" se transformaría en "impensable" porque el niño ignora la existencia del secreto pero puede percibir en sí mismo sensaciones, emociones, imágenes, o extrañeza por acontecimientos que no se explican por su propia vida psíquica o familiar. Este sujeto podría desarrollar síntomas o podría socializarse en 
ocupaciones que impliquen la búsqueda del pasado, como la historia, la arqueología o el psicoanálisis. (Tisseron, 1995 p. 19)

Las influencias intergeneracionales (entre generaciones adyacentes) diferirán de las que suceden transgeneracionalmente, ya que en este caso, los contenidos psíquicos de un niño pueden estar marcados por el funcionamiento psíquico de abuelos o ancestros que los niños no han conocido, pero cuya vida psíquica ha marcado a sus propios padres. (Tisseron y otros, 1995). Dice Tisseron (1995, p. 17): “El fantasma resulta de los efectos sobre el inconciente de un sujeto, de la cripta de otro, es decir, de su secreto inconfesable".

En la historia que la película narra, el protagonista cuando adulto, es un profesional de la salud mental; lo que permite inferir cuán importante fue su travesía personal hacia su madurez psíquica.

Considerando el análisis como proceso, cabe destacar el efecto terapéutico de la relación analista-analizante que se va construyendo transferencia mediante. Concepto que en El Esquema (1939, p. 175), Freud explica que surge porque el paciente suele ver en el analista “....un retorno-reencarnación- de una persona importante de su infancia, de su pasado y por eso transfiere sobre él sentimientos que sin duda se referían a ese arquetipo".

Durante el proceso analítico, la dirección de la cura utiliza como herramienta la transferencia, recurso mediante el cual el analista trabaja para el levantamiento de las represiones y así, a través de la repetición y rememoración, intenta restablecer un sentido donde alguna vez se han producido lagunas mnésicas o traumas. Más adelante se sustituye la noción de trauma por la de fantasma que involucra el orden simbólico de la sustitución y el desplazamiento y la cura entonces se orienta no tanto al núcleo del acontecimiento traumático, sino a deshacer fijaciones pulsionales. De esta manera, el analizando revive situaciones que repite en transferencia intentando resolver dichas situaciones. 
En Tótem y Tabú (1913), Freud señala que nada de lo retenido en una generación podrá permanecer completamente inaccesible a las generaciones siguientes. Podrían manifestarse síntomas, como si fueran huellas que ligan a las generaciones entre sí en un sufrimiento sostenido en una causa que podrá ser desconocida. Se trataría de una transmisión de cosa, inaccesible por las palabras.

\section{Una viñeta:}

Un joven abogado, nieto de sobrevivientes de la Shoah, dijo en una nota que le hicieran, para conmemorar un nuevo aniversario de ese horror: "Me pregunto si mis estados de angustia, que a veces no hallan explicación en razones objetivas de mi mundo fenoménico, no tendrán que ver con la historia de mis abuelos. Por de pronto, los alambres de los barrios cerrados y los crepúsculos vespertinos me producen una sensación de malestar y cierta aura de tristeza. También me cuesta despedirme de mis seres queridos, como si estuviera latente esa situación que atravesó mi abuela, abruptamente separada de sus padres, que de un día para otro, no volvió a ver".

\section{Conclusiones y reflexiones.}

Este trabajo toma una película para relatar y mostrar aspectos y conceptos de la teoría psicoanalítica. La película permite situarse frente a la realidad como ficción (o frente a la ficción como realidad). La misma, es el escenario donde transcurren las escenas que movilizan la reflexión sobre las diferentes temáticas planteadas. En la pantalla las imágenes tejen un velo que encubre y al mismo tiempo revela algo que se da a ver.

El cineasta compone una ilusión en la que el espectador se encuentra comprometido y de este modo lo afecta.

En el presente trabajo se intentó pensar una manera posible de ampliar la escucha y comprensión del analista para ayudar al analizando a reparar heridas causadas por traumas provocados por secretos familiares y violencia social. 
Mediante el recorrido de la película se trató de demostrar el efecto que se produce sobre las generaciones cuando situaciones silenciadas se transmiten sin palabras generando muchas veces traumas.

"El psicoanálisis sería una vía regia hacia la ruptura de las denominadas criptas" (Abraham y Torok, 2005), mediante la simbolización que produce palabra donde no la hubo.

Existe un vínculo dialéctico entre la singularidad del sujeto y el legado cultural del contexto en el que adviene. Lo expresan los versos del texto Agua, fuego, tierra y viento de Paz Martínez:

" cuando yo te abrazo no te abrazo sola, te abraza conmigo una eternidad... "

Si bien genocidios y masacres son innumerables a lo largo de la historia de la civilización, el término Shoah, remite a la crueldad inconmensurable con la que se perpetraron asesinatos masivos en nombre de la humanidad y la civilización, usando la más avanzada tecnología de la época.

La característica específica de las masacres genocidas nacionalsocialistas es que se trató de un plan planeado y ejecutado por la autoridad estatal, que tenía y ejercía, un poder ilimitado de definición y exclusión de grupos de su población, calificándolos de "indeseables", "peligrosos", "inútiles", "contaminantes", entre otros denigrantes calificativos; privándolos de sus derechos y posteriormente, aniquilándolos físicamente.

La Shoah constituye el paradigma del horror supremo cometido por seres humanos a otros seres humanos, el paradigma del mal radical. Entonces, reflexionar e interpelar la Shoah y sus consecuencias, permite pensar en todas las modalidades de violencia social. Hay quienes creen que el pasado debe cerrarse y mirar hacia delante sin volver la mirada hacia atrás. ¿Se puede?, y ¿Qué sucede cuando se da por cerrado un tema y muchas décadas después, de pronto irrumpe desde el registro que Lacan denomina Real? 
El fluir eterno de la Historia y sus guerras, va encontrando su cauce y sus efectos se manifiestan, a veces a largo plazo, a través del tiempo y del espacio, como "restos radiactivos" en la intersección entre el presente y el pasado, entre la presencia y la ausencia (Yolanda Gampel, 2006)

Así como en lo individual el síntoma puede ser expresión de sucesos acaecidos en generaciones que antecedieron al sujeto, surge la pregunta si desde una perspectiva social, acontecimientos violentos del presente podrían ser "síntoma" de acontecimientos ahogados en las profundidades del tiempo.

"Mirar atrás" no significa quedar fijado al pasado, como lo representa la bíblica imagen de la esposa de Lot convertida en estatua de sal, sino por el contrario, permitiría un análisis de la experiencia y de esta manera se podría enriquecer el conocimiento y se favorecería la expansión hacia caminos que siempre se van abriendo al paso del progreso del ser humano, de modo que cese la repetición de lo que ya ocurrió y en parte fue facilitado por lo que no "se quiso/quiere ver". Por eso, memoria, recuerdo, transmisión, imagen, palabra; pueden ser tramitadores del legado que viaja de generación en generación, a través del tiempo y el espacio; ya que el psicoanálisis parte del supuesto de un "aparato psíquico extendido en el espacio" y desarrollado de acuerdo a las necesidades de la vida (Freud, 1939, p.198), como expresiones de la pulsión erótica, de vida.

El psicoanálisis como "arte/ciencia" provee dispositivos o modos de encontrar nexos y relaciones de dependencia entre el mundo exterior y el mundo anímico, del pensamiento y los afectos, que "habilitan" a una mayor comprensión del medio en que el sujeto humano habita, a prever situaciones o condiciones posibles o probables, y en algunos casos, a modificarlo ( Freud, 1939).

\section{Bibliografía}

Abraham, Nicolas y Torok, María. La corteza y el núcleo. Editorial Amorrortu, Buenos Aires, 2005. 
Diacovetzky, Rut. (2007) Monografía: Resonancias de lo indecible al paso de las generaciones.

Faimberg, Haydée. El telescopaje de generaciones. Editorial Amorrortu , Buenos Aires, 2006.

Freud, Sigmund (1896). Carta 52 (1896), en Obras Completas, tomo I. Ed. Amorrortu. Buenos Aires, 2001.

- (1913). El interés por el psicoanálisis. II El interés del psicoanálisis para las ciencias no psicológicas. Obras Completas, tomo XIII, Ed. Amorrortu, Buenos Aires, 2003.

- (1914). Introducción del Narcisismo. Pág 76, en Obras Completas. tomo XIV. Ed. Amorrotu, Buenos Aires, 2000.

- (1915). Lecciones de introducción al Psicoanálisis en Obras Completas de Ed. Amorrortu, tomo XV, Buenos Aires.

- (1916-1917). Conferencias de introduction al psicoanálisis (Parte III) en Obras Completas, tomo XVI, Pág. 335-336. Editorial Amorrortu, Buenos Aires, 2000.

- (1917-1919). De la historia de una neurosis infantil (el "Hombre de los Lobos") en Obras Completas, tomo XVII, Pág.89. Editorial Amorrortu, Buenos Aires, 1999.

- (1921). Psicología de las masas y análisis del yo, en Obras Completas, tomo XVIII, capítulo VII. Ed. Amorrortu, Buenos Aires, 2001.

- (1927-1931). El malestar en la cultura, en Obras Completas, tomo XXI Editorial Amorrortu, Buenos Aires, 2001.

- (1937). Construcciones en el análisis, en Obras Completas, tomo XXIII, Ed. Amorrortu, Buenos Aires, 2001.

- (1939). El Esquema, nota introductoria por James Strachey, en Obras Completas, tomo XXIII, pág. 136. Ed. Amorrortu, Buenos Aires, 2001.

Fudín, Mónica (2005). Psicoanálisis y cine: Arte, Artista y Espectador. Trabajo presentado en El Sigma, espacio de Internet, cine y psicoanálisis. Dispositivo del cine. Septiembre 2005.

Hassoun, Jaques (1994). Contrabandistas de la memoria. Ediciones de La Flor, Buenos Aires, 1996.

Kaës René (1993). Transmisión de la vida psíquica entre generaciones Amorrortu , Buenos Aires, 1996.

- (1993) Transmisión de la vida psíquica entre generaciones. Ed. Amorrortu, Buenos Aires, 1996.

Kertész, Imre. Yo, otro. Crónica del cambio. Editor Acantilado, Barcelona, 2002. Epígrafe 
Lacan, Jacques. La Familia. Editorial Argonauta, Buenos Aires, quinta edición, julio 2003.

Laplanche,Jean (1996). Diccionario de psicoanálisis. Ed. Paidós, Buenos Aires, 1967.

Mannoni, Maud (1967). El niño, su enfermedad y los otros, novena reimpresión, Ediciones Nueva Visión, Buenos Aires, 2007.

Peskin, Leonardo; La realidad, el sujeto y el objeto. Editorial Paidós, Buenos Aires, 2015.

- (2003). Los Orígenes del Sujeto, pág. 186, Ed. Paidós, Buenos Aires, 2003

Tisseron y otros (1995). "El psiquismo ante la prueba de las generaciones" Pág. 19, Editorial Amorrortu Bs. As. 1995

- (1995). “El psiquismo ante la prueba de las generaciones" Pág. 14, Editorial Amorrortu, Bs. As. 1995

Zimmerman, Daniel (1993). Ficción y Fantasma. Pág. 16. Ricardo Vergara Ediciones, Buenos Aires, 1993.

- (2000). Contornos de lo real. La verdad como estructura de ficción. Editorial Letra Viva, Buenos Aires, 2000.

Link para ver sinopsis de la película, sobre el material utilizado en la monografía:

1) bit.ly/monografíalegados

2) en YouTube: Legados, peregrinos del tiempo. 
